\title{
Decontamination and Decommissioning of the Tokamak Fusion Test Reactor
}

\author{
E. Perry, J. Chrzanowski, K. Rule, R. Strykowsky, M. Viola, M.Williams \\ Princeton Plasma Physics Laboratory, P.O. Box 451, Princeton, NJ 08543
}

I. INTRODUCTION

II. Project Overview

The Tokamak Fusion Test Reactor (TFTR) is a one-of-a-kind, tritium-fueled fusion research reactor that ceased operation in April 1997. The Decontamination and Decommissioning (D\&D) of the TFTR is scheduled to occur over a period of three years beginning in October 1999. This is not a typical Department of Energy D\&D Project where a facility is isolated and cleaned up by "bulldozing" all facility and hardware systems to a greenfield condition. The mission of TFTR D\&D is to: a) surgically remove items which can be re-used within the DOE complex, b) remove tritium contaminated and activated systems for disposal, c) clear the test cell of hardware for future reuse, d) reclassify the D-site complex as a non-nuclear facility as defined in DOE Order 420.1 ("Facility Safety") and e) provide data on the D\&D of a large magnetic fusion facility.

The 100 cubic meter volume of the donut-shaped reactor makes it the second largest fusion reactor in the world. The record-breaking deuterium-tritium experiments performed on TFTR resulted in contaminating the vacuum vessel with tritium and activating the materials with 14 Mev neutrons. The total tritium content within the vessel is in excess of 7,000 Curies while dose rates approach 75 $\mathrm{mRem} / \mathrm{hr}$. These radiological hazards along with the size and shape of the Tokamak present a unique and challenging task for dismantling.

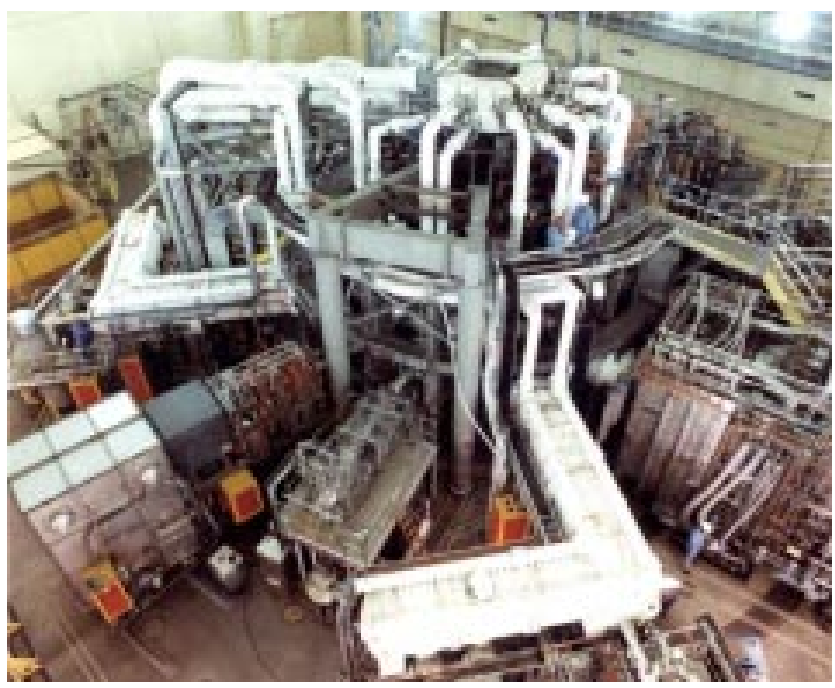

The Decommissioning and Decontamination of the Tokamak Fusion Test Reactor (TFTR) at the Princeton Plasma Physics Laboratory (PPPL) will take three years and cost $\$ 46 \mathrm{M}$.

During the first year of TFTR D\&D, engineering studies will be performed to address the tokamak dismantlement and removal. At the same time, removals will begin for the appendages to the vacuum vessel, other items in the test cell and the vacuum piping in the test cell basement. These removals should conclude during the second year. Also during the second year a tokamak removal design review will be conducted.

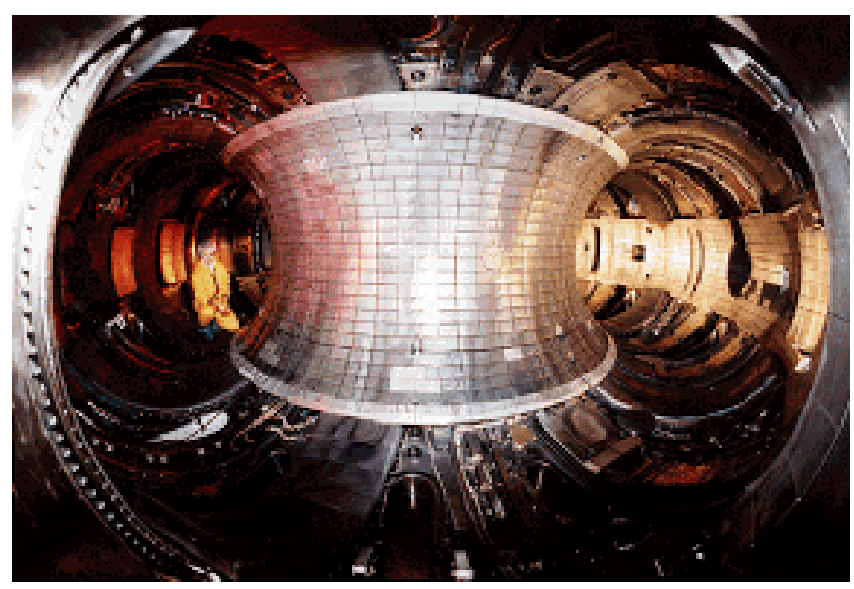

Figure 2 - Inside of TFTR vacuum vessel showing the carbon tiles which hold most of the tritium inventory.

During the third year of TFTR D\&D the removal of the tokamak itself will occur. This sequence will begin with the removal of the vacuum pumping ducts, umbrella structure and PF magnets. This will be followed by the segmentation of the vacuum vessel using the diamond wire cutting technique. Once all of the activated/contaminated waste has been packaged and shipped for burial, the test cell walls and floors will be decontaminated.

Figure 1 - TFTR 


\section{Project Management}

The TFTR D\&D Project has been organized into a Work Breakdown Structure with six main areas: Engineering, Field Operations, Project Management, Health Physics / Safety, Radwaste Operations and Project Contingency. Both Engineering and Field Operations are further divided into the four areas of: General Oversight / Planning, Area Preparations, Non-Tokamak Removals and Tokamak Removals. Project Management is divided into the areas of Project Office, Work Control Center, and Configuration / Document Control.

The Work Control Center is a process whereby Engineering prepares work packages that include procedures (with labeled color photos of the items to be removed), drawings and a job hazard analysis and then submits these packages to the Work Control Center (WCC). The WCC then reviews the packages for completeness, ensures that all prerequisites are completed prior to releasing a package to the field, arranges for all permits (area work permits, radiation work permits, flame permits, etc) and then schedules the work in a manner that coordinates all activities in process. The WCC runs a plan of the day meeting at the start of each day, issues packages to the field crews, and arranges pre-job briefings for all new packages. The WCC also arranges for the resolution of any problems/questions encountered by the field crews and if such resolution cannot be made promptly, the WCC takes back that work package and issues another one to the field crew so they remain productive while the issues are resolved.

The Field Crews will perform and/or verify the safing / lockout-tagout as required and then will perform the fieldwork per written procedure. They are responsible for contacting the WCC if a problem or question arises. They are also responsible for returning the work packages to the WCC at the end of each shift so the packages can be stored in a single location. When a work package has been completed, the field crews will return the package to the WCC. The WCC will then transmit the package to Engineering so that drawings can be updated or voided as required.

\section{D\&D Sequence}

The TFTR D\&D field work is divided into three areas: area preparation, non-tokamak removals, and tokamak removals. Area preparation prepares the Test Cell areas for the start of D\&D removal activities and includes shield wall removals, modifications to the Test Cell facility, and the set-up of areas for processing, packaging and surveying the radioactive waste. Non-tokamak removals include the safing of all electrical systems in the Test Cell and the Test Cell Basement as well as the removal of components on the floor (EL 100') surrounding the tokamak pedestal (EL 102') and components above the Umbrella structure over the tokamak. Tokamak removals include the shutdown of the vacuum vessel systems, the removal of the remaining components in the Test Cell, and the final decontamination of the Test Cell. Also included in this final phase is the removal of all tritium-associated equipment and components in the Test Cell Basement.

V. New Technology

The decommissioning of the tokamak is based on the plan to fill the vacuum vessel with lightweight concrete and then cut it into ten segments, using diamond wire cutting (DWC), for transportation and radwaste burial at Hanford. The feasibility of the diamond wire cutting of a concrete filled stainless steel vessel was demonstrated at PPPL during the late summer of 1999. This demonstration was funded by the EM-50 D\&D Focus Area which is managed by the Federal Energy Technology Center in Morgantown, West Virginia and was developed and performed through joint efforts of the Florida International University Hemispheric Center for Environmental Technology and the Princeton Plasma Physics Laboratory. The diamond wire cutting technology vendor was Bluegrass Concrete Cutting, Inc, Greenville, Alabama.

During this diamond wire cutting demonstration, the diamond wire rope was used to segment a surrogate of the TFTR vacuum vessel and it successfully cut through several layers of 304 SS and Inconnel. Cutting was performed on several full-sized mock-ups of the TFTR vacuum vessel using different void fillers to evaluate the effectiveness of each. Standard concrete, low density concrete and foam were used. The mock-up filled with Rheocell-15, a low-density concrete $\left(35 \mathrm{lbs} / \mathrm{ft}^{3}\right)$, provided the best matrix for cutting. This material provided the necessary structural support while reducing heat generation, which enhanced wire performance. In addition, this matrix enabled the first successful deployment of liquid nitrogen as a cooling media. Water is the typical cooling media for DWC, however, the use of liquid nitrogen in many radiological applications, such as those involving tritium as is the case for TFTR, may be preferable to water. Full reports on this demonstration should be available in late 1999.

\section{Tritium Removal and Control}

The present tritium inventory at PPPL includes 7,292 $\mathrm{Ci}$ in the vacuum vessel, 2,500 $\mathrm{Ci}$ in the Tritium Purification System (already disconnected from all other systems), and $922 \mathrm{Ci}$ in other systems. In the baseline plan for TFTR D\&D, the removal of all carbon tiles inside the vacuum vessel will be completed prior to filling the vessel with concrete and segmenting it. This bulk removal will be done to reduce the exposure hazards to personnel during vessel segmentation. The analysis of tiles removed from the vessel in early October 1999 as well as the airborne particulate analysis from this summer's Diamond Wire Cutting trials, will be factored into the decision of how 
many and which tiles should be removed prior to vessel segmentation.

Throughout the TFTR D\&D, the main concern will be for the safety and protection of the workers. ALARA studies will be performed prior to the start of any activities involving opening components which may contain tritium, and engineering controls such as containment and "elephant trunk" ventilation will be used for all "tritium line breaks".

VII. Radioactive Waste

TFTR D\&D is expected to generate 44,658 cubic feet of tritiated and activated material. About 20,83 cubic feet of this will be standard waste (B25 boxes) and the balance will be in non-standard or no packaging form. All shipments will be LSA or type A quantities with normal shipments limited to 40,000 lb. Special shipments will include the 10 vacuum vessel segments and $20 \mathrm{TF}$ coils (special permits for size and weight).

Summary

The Decontamination and Decommissioning (D\&D) of TFTR will occur over three years starting in October 1999. The segmentation of the vacuum vessel will be done by filling the vessel with lightweight concrete and then cutting it into ten segments using diamond wire cutting. The D\&D of TFTR will be done safely, in a cost-effective manner, and within schedule. 


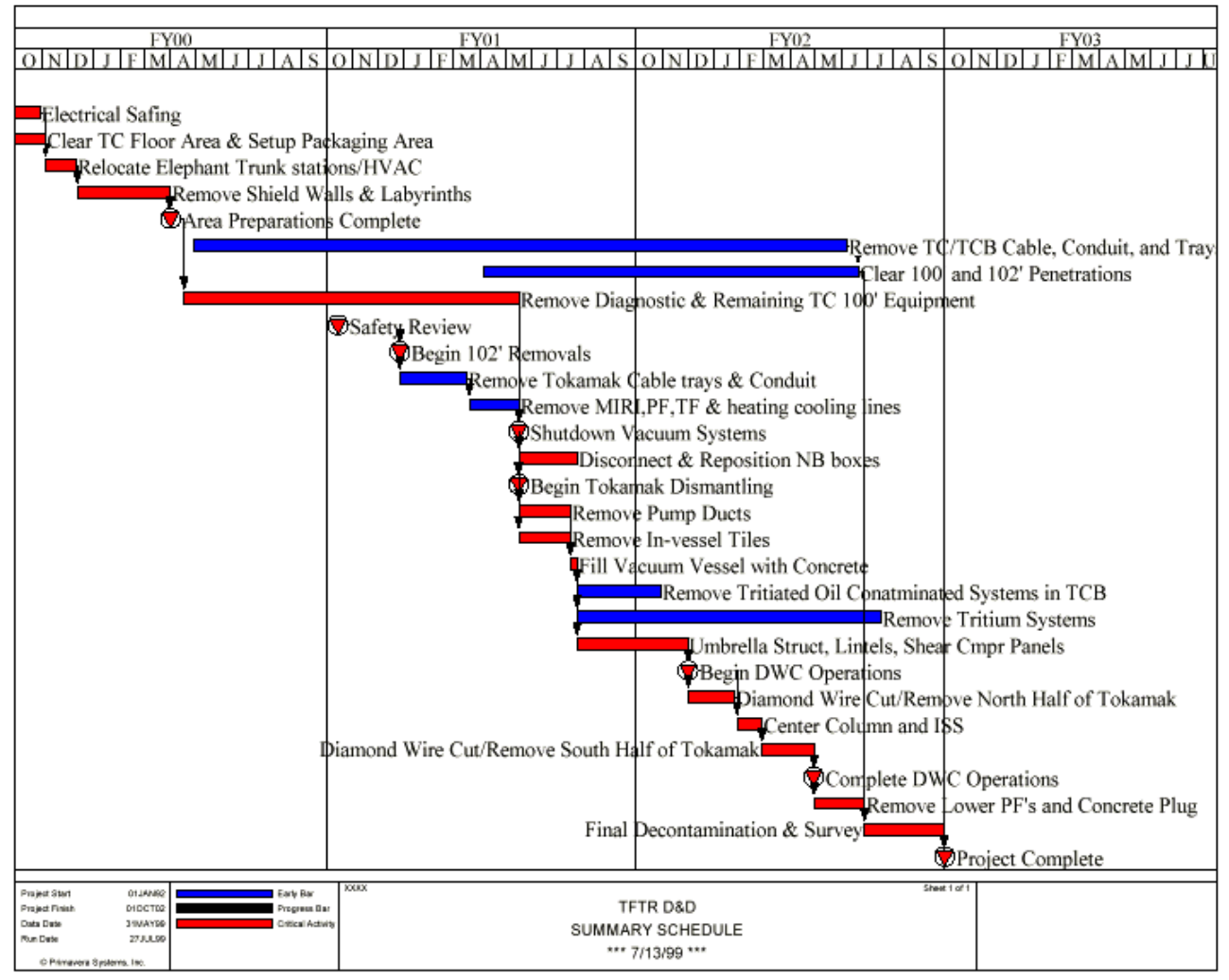

